\title{
Os Recursos Educacionais Abertos (REA) Como Apoio à Formação Continuada Docente
}

\author{
Open Educational Resources (OER) to Support Continuing Teacher Training
}

\author{
Aline da Costa Silva Santos ${ }^{\mathrm{a}}$; Thássya Maria Dias de Oliveira ${ }^{\mathrm{b}}$; Mariza da Gama Leite de Oliveira*b
}

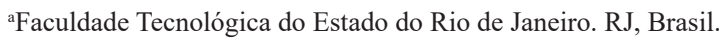

bUniversidade Federal do Estado do Rio de Janeiro. RJ, Brasil.

*E-mail: marizagoliva@gmail.com

\begin{abstract}
Resumo
O artigo analisa a contribuição das novas tecnologias da informação e comunicação para o trabalho docente na atualidade. Busca contribuir para o aprimoramento da formação continuada de professores, conscientizando-os da necessidade de conhecerem os principais desafios que as mudanças tecnológicas trazem para o ensino; pretende também lançar um olhar crítico sobre a eficácia das políticas públicas, no sentido de inserir nas escolas públicas recursos e profissionais capacitados. Como apoio à formação continuada docente, são apresentados os recursos educacionais abertos (REA) que promovem a educação aberta, incentivam práticas de colaboração e compartilhamento, facilitam o acesso ao conhecimento e incentivam os professores e estudantes a serem coautores na produção de materiais para fins educacionais. A metodologia utilizada é a pesquisa bibliográfica, incluindo busca a sites como domínio público, TV escola e portal do professor. O estudo concluiu que apesar das falhas nas políticas públicas, e a falta de investimento em informática educativa na educação pública, há repositórios que podem contribuir para a formação continuada de professores, de iniciativa do ministério de educação; mas infelizmente são pouco visitados pelos docentes ou usados pelas instituições para formação em serviço.
\end{abstract}

Palavras-chave: Recursos Educacionais Abertos. Formação Continuada. Ferramentas Digitais.

\begin{abstract}
The article analyzes the contribution of new information and communication technologies to teaching work today. It seeks to contribute to the improvement of the continuing education of teachers, making them aware of the need to know the main challenges that technological changes bring to teaching; it also intends to take a critical look at the effectiveness of public policies, in the sense of inserting resources and trained professionals in public schools. In support of continuing teacher education, open educational resources (OER) are presented that promote open education, encourage collaboration and sharing practices, facilitate access to knowledge and encourage teachers and students to be co-authors in the production of materials for educational purposes. The methodology used is bibliographic research, including search for sites such as public domain, TV school and teacher portal. The study concluded that despite the flaws in public policies, and the lack of investment in educational computing in public education, there are repositories that can contribute to the continuing education of teachers, initiated by the ministry of education; but unfortunately they are seldom visited by teachers or used by institutions for in-service training.
\end{abstract}

Keywords: Open Educational Resources. Continuing Education. Digital Tools.

\section{Introdução}

A experiência de uma das autoras com a informática vinculada à educação, ocorreu somente a partir do seu ingresso no curso de graduação em Pedagogia, na modalidade EaD; e durante o curso, na fase do estágio supervisionado, a mesma deparou-se com a precariedade ou a inexistência da informática educativa no dia a dia da sala de aula. Tem-se conhecimento de que essa carência nem sempre ocorre pela falta de equipamentos; em muitas situações deve-se à falta de profissionais capacitados, incluindo os professores. Existem inúmeros softwares com conteúdo educativo, que poderiam dar suporte ao trabalho docente. Mas será que os docentes estão capacitados para usá-los?

Num passado não muito distante, realizávamos pesquisas em bibliotecas com uso de revistas e enciclopédias, num longo processo de leitura, análise e síntese; no entanto, com a chegada da internet, essa busca se modificou. Quantas vezes digitamos um tema no site de buscas e ao abrirmos o primeiro link que surge, usamos o recurso CTRL + C seguido do CTRL + V, sem ler detidamente e analisar a informação, e sem confirmar se é confiável ou não? Assim, questiona-se: $\mathrm{O}$ que a escola tem feito para modificar essa realidade? A formação na educação básica tem contribuído para a interação entre a educação e a informática? Como o professor tem se capacitado?

Este artigo pretende pensar com o leitor a respeito das transformações que as novas tecnologias da informação e comunicação trouxeram para a humanidade, refletindo-se no campo educacional; compreender o papel do professor como mediador entre os educandos e essas novas tecnologias; e conhecer ferramentas digitais que contribuem para a prática 
docente.

\section{Desenvolvimento}

\subsection{Metodologia}

A metodologia adotada nessa abordagem é a pesquisa bibliográfica, com base em leituras realizadas pelas autoras durante cursos de extensão e capacitação docente. Devido aos limites desse artigo, cerca de dez obras fundamentam o desenvolvimento da temática, que primeiramente aborda o que vem a ser Novas Tecnologias da Informação e Comunicação (NTIC) e Sociedade da Informação; em seguida analisa o papel do educador como mediador entre o educando e as NTIC e a necessidade do seu constante aperfeiçoamento; e por fim apresentada algumas ferramentas digitais que funcionam como facilitadoras do trabalho docente, as quais são pouco exploradas, com destaque para os Recursos Educacionais Abertos (REA).

\subsection{As NTIC e a Sociedade da Informação}

Entende-se por Novas Tecnologias da Informação e Comunicação (NTIC), os artifícios utilizados para agilizar, horizontalizar e facilitar a captação, a transmissão e a distribuição de informações em rede, surgidos no contexto Revolução Informacional, Revolução Telemática ou Terceira Revolução Industrial, e desenvolvida gradativamente desde a metade da década de 1970, atingindo seu auge no ano de 1990.

As NTIC avançaram na medida em que ocorreu o desenvolvimento das tecnologias digitais. De acordo com Lopes e Melo (2014, p. 50), o seu surgimento não tem uma definição exata, porém, de acordo com a predominância de determinadas tecnologias e as transformações associadas a elas, é possível identificar pelo menos três períodos da história das NTIC.

Para Velloso (2014) as novas tecnologias estão associadas à interatividade e à quebra do modelo comunicacional no qual a informação é transmitida de modo unidirecional, adotando o modelo em que aqueles que integram redes de conexão atuam no envio e recebimento das informações.

Diversas transformações ocorreram em praticamente todos os setores da sociedade: social, econômico, político e cultural. Com elas surgiram novas formas de se relacionar, novas possibilidades, novos costumes, novas fontes de informação, e enfim novos desafios a serem superados, já que o avanço tecnológico é constante e rápido, e nem sempre estamos aptos a acompanha-lo.

Novos hábitos de consumo, novas modalidades de lazer, novas áreas de atuação profissional, novos comportamentos, novos modos de pensar, entre outras transformações, se tornam possíveis graças ao surgimento de determinadas tecnologias. Esse momento parece propício não apenas para o estudo das relações entre humanos e técnicas, mas também para o questionamento desses campos como polos opostos (LOPES; MELO, 2014, p.50).

Ao longo dos anos surgiram inúmeros tipos de NTIC, com destaque para a internet, que foi o principal e mais importante advento, responsável por tantas transformações. Particularmente a internet, "trouxe grandes possibilidades de inovação no processo de comunicação e as distâncias geográficas deixaram de ser barreiras para sua concretização" (OLIVEIRA, 2003, p.92).

A internet abriu um leque das mais diversas opções de uso, tornando-se responsável pela formação de uma nova estrutura social, com profundas transformações no setor industrial, nova capacidade de produção e nova relação de consumo em massa da informação, causando impactos nos mais variados segmentos em todo o mundo. Assim, a sociedade deixou de ser industrial, e tornou-se a Sociedade da Informação, expressão que veio substituir o conceito de Sociedade Pós-Industrial, e transmitir o conteúdo específico do novo paradigma técnicoeconômico, o qual Werthein (2000, p.71-72) esclarece:

A realidade que os conceitos das ciências sociais procuram expressar refere-seàs transformações técnicas, organizacionais e administrativas que têm como 'fator-chave' não mais os insumos baratos de energia - como na sociedade industrial - mas os insumos baratos de informação propiciados pelos avanços tecnológicos na microeletrônica e telecomunicações. Esta sociedade pós-industrial ou 'informacional', como prefere Castells, está ligada à expansão e reestruturação do capitalismo desde a década de 80 do século que termina. As novas tecnologias e a ênfase na flexibilidade - ideia central das transformações organizacionais - têm permitido realizar com rapidez e eficiência os processos de desregulamentação, privatização e ruptura do modelo de contrato social entre capital e trabalho característicos do capitalismo industrial.

Como dito acima, a expressão Sociedade Pós-Industrial vem sendo substituída por Sociedade da Informação, caracterizada pelo uso dos insumos baratos de informação propiciados pelos avanços tecnológicos na microeletrônica e telecomunicações. No campo educacional, foram processadas inúmeras modificações com o desenvolvimento da Sociedade da Informação.

A partir da década de 1970, a tecnologia da informação (TI), começou a chegar nas escolas com a instalação de computadores e periféricos (impressoras, drivers externos, scanners entre outros). Em seguida, chegou a Internet, que trouxe consigo os computadores em rede, e-mail e ferramentas de busca; e devido a sua pluralidade, criou-se a expressão Novas Tecnologia da Informação e Comunicação. Com sua chegada, abriram-se inúmeras possibilidades de distribuição social do conhecimento, e essas tecnologias tornam-se cada vez mais necessárias e indispensáveis nas novas formas de ensino e aprendizagem; porém, as discussões sobre essas tecnologias como parte do processo de aprofundamento nas mudanças da sociedade e seus impactos educacionais, ainda não tem recebido a devida atenção.

\subsection{O professor como mediador no uso das NTIC e a formação continuada}

Segundo Baladeli, Barros e Altoé (2012) a formação de sujeitos críticos e dotados de competências como a criatividade, 
a flexibilidade, a capacidade de resolver problemas, tornam-se atributos indispensáveis para atuação na sociedade atual.

As mudanças e os avanços tecnológicos ocorrem de forma muito veloz; máquinas e softwares são criados ou atualizados a todo momento. As mudanças na informática criam uma ampla gama de possibilidades de usos do computador, exigindo muito mais da formação do professor; e paradoxalmente, essa velocidade acaba o paralisando (LEITE; RIBEIRO, 2012).

Leite e Ribeiro (2012) ressaltam que existe por parte de muitos professores uma enorme resistência à utilização das novas tecnologias na educação, pois na maioria das vezes esses professores não querem mudar a metodologia com que se sentem mais seguros.

Da mesma forma pensam Valente e Almeida (1997), que sugerem uma nova dinâmica de formação docente, em que o professor necessita ser formado para assumir o papel de facilitador na construção de conhecimentos, e deixar de ser o entregador das informações para os educandos. Assim, ele precisa tanto ter o domínio das ferramentas digitais quanto integrar esse material às atividades curriculares.

É imprescindível avaliar com transparência as ações que objetivam fornecer uma formação no sentido de proporcionar aos educandos um ambiente alfabetizador que compreenda a constante mudança da sociedade, usando a informática a seu favor e de todos a seu redor, com subsídios teórico-metodológicos que possam ir ao encontro das reais necessidades do cotidiano da sala de aula. Cabe, portanto, ao professor, desempenhar um papel desafiador. Além disso, servir como modelo de aprendiz e ter um profundo conhecimento dos pressupostos teóricos e práticos que envolvem o uso das ferramentas digitais (VALENTE, 1999).

É necessário que a escola esteja preparada para aderir às novas tecnologias educacionais, tendo em vista que a inclusão dessa modalidade, que não é tão nova assim, proporciona um novo conceito em busca da construção do conhecimento de todos os educandos.

A internet está acessível em quase todos os lugares. E pode ser usada tanto no computador, quanto no celular, tablet, smartphone etc.; e tem proporcionado na sala de aula uma série de benefícios. Logicamente o seu uso pedagógico requer uma infraestrutura bem montada, em laboratório que tenha computadores modernos, com acesso à internet $\mathrm{e}$ professores de informática educativa. Esse professor deve servir de interlocutor com os demais professores da turma, para selecionar jogos educativos e atividades que venham a reforçar o conteúdo trabalhado em sala de aula por esses professores.

Como a presença de professores de Informática Educativa não é uma realidade na maioria das escolas públicas, os professores devem estar em constante busca de capacitação e aprimoramento, uma vez que os educandos tendem a estar à frente destes no domínio das tecnologias digitais. $\mathrm{Na}$ Sociedade da Informação e do Conhecimento, a educação escolar disputa a atenção dos alunos com outros espaços sociais mais atraentes e dinâmicos; por isso a necessidade de mudança na atuação do professor. É importante lembrarmos que a formação profissional do professor não pode acontecer apenas na graduação, sendo necessário ter continuidade para oferecer-lhe condições de se apropriar dela, relacionando a teoria e a prática.

As políticas educacionais devem passar por constantes reformulações a fim de mudar de vez o paradigma na formação do professor, para que o profissional da educação se capacite, através de uma formação continuada e tenha condições para ser capaz de realizar uma prática pedagógica menos tradicional e mais objetiva.

Entende-se por formação continuada, de acordo com Leite e Ribeiro (2012), o aperfeiçoamento/capacitação do professor que já detém algum tipo de conhecimento sobre essas tecnologias e está em exercício profissional. Os autores explicam que apesar de existirem algumas capacitações, estas ainda são em pouca quantidade e não atendem à demanda; ainda faltam mais ações governamentais para o aperfeiçoamento dos professores.

$\mathrm{Na}$ busca pela excelência no processo de ensino, os professores devem assimilar bem as suas novas competências. A transformação do ensino deve ir além do uso de recursos tecnológicos, sua postura passa de transmissor absoluto de conhecimentos, para o facilitador de descobertas. Portanto, sua atitude deve ser a de buscar a constante profissionalização, por meio da educação continuada, conforme já evidenciamos.

Uma das soluções para tentar viabilizar a capacitação de professores tem sido os cursos à distância, evitando deslocamentos. Esta modalidade de Educação tem ganhado destaque atualmente, desde o início da pandemia do Covid-19, no ano de 2020.

A seguir, apresentaremos algumas ferramentas do âmbito das NTIC, que podem tanto facilitar a prática docente, quanto melhor capacitá-lo.

\subsection{Ferramentas facilitadoras da prática docente}

As consequências (positivas e negativas) provenientes da aplicação da tecnologia no âmbito educacional dependem do uso que fazemos dela e da sua influência nas rotinas de trabalho, afirmam Barroso e Antunes (2015). As NTIC são ferramentas usadas com o objetivo de agilizar, horizontalizar e facilitar a captação, a transmissão e a distribuição de informações em rede. Os autores explicam que como ferramentas de ensino, o uso das mídias é favorecido por meio da utilização de recursos tecnológicos variados, tais como slides, exercícios virtuais, vídeos, plataformas de Ensino a Distância (EaD), web conferências, lousas digitais, e-mails, armazenamento em nuvens, entre outros; e que um grande benefício da tecnologia para a educação é a flexibilidade de tempo e espaço, que torna possível o acesso dos usuários ao material publicado pelos professores e alunos com a ajuda da internet, permitindo que o conteúdo seja consultado de qualquer lugar e em qualquer momento. 
Deve-se ter em vista que as tecnologias digitais podem ser grandes aliadas dos métodos empregados dentro de sala de aula, cabendo a nós sabermos dosar o seu uso para que ela não se torne apenas uma ferramenta isolada, e sim um componente do processo de aprendizagem, no qual professor e estudantes se sintam beneficiados com os recursos e aparatos utilizados. É necessário que o professor se conscientize da importância de se familiarizar com a cultura digital e assim, de acordo com a experiência que já possui em relação a prática de ensino, possa pensar em práticas pedagógicas para aplicar com seus educandos, promovendo adequações, sempre que necessário.

A seguir apresentamos algumas ferramentas digitais disponíveis para aplicação na área educacional com uma breve descrição das mesmas, que representam parte do levantamento feito por Barroso e Antunes (2015).

Quadro 1 - Levantamento das ferramentas digitais disponíveis para aplicação na área educacional

\begin{tabular}{|c|c|}
\hline Ferramenta & Descrição \\
\hline Dropbox & $\begin{array}{l}\text { Disco rígido virtual (ambiente para armazenamento) com vários gigabytes (GB) gratuitos e acessível por uma } \\
\text { quantidade ampla de dispositivos. }\end{array}$ \\
\hline Google Drive & $\begin{array}{l}\text { Ferramenta disponibilizada pelo Google que se assemelha a um espaço virtual gratuito, somado às múltiplas } \\
\text { ferramentas de criação de documentos, planilhas, arquivos e pastas. }\end{array}$ \\
\hline CloudMagic & $\begin{array}{l}\text { Extensão e aplicativo multidispositivo para buscar informações e arquivos armazenados simultaneamente no } \\
\text { Gmail, Twitter, Facebook, Evernote e demais serviços. }\end{array}$ \\
\hline Jumpshare & $\begin{array}{l}\text { Útil para compartilhar documentos de forma ágil e permitir sua visualização online, além de seu download. } \\
\text { Os arquivos ficam disponíveis na nuvem (online) durante duas semanas. }\end{array}$ \\
\hline Weebly & $\begin{array}{l}\text { Ferramenta de criação de websites que se destaca por seu agradável editor visual e seu baixo custo, a começar } \\
\text { por um acessível plano gratuito. }\end{array}$ \\
\hline ePubBud & Espaço para criar livros virtuais (e-books) e publicá-los. Também serve para buscar exemplares. \\
\hline Text2MindMap & $\begin{array}{l}\text { Ferramenta útil para planejamento; permite criação de mapas mentais através de um pequeno editor de texto e } \\
\text { um quadro interativo fáceis de usar. }\end{array}$ \\
\hline EdCanvas & Para criar e compartilhar as lições das classes em formato digital. \\
\hline TubeBox & Ferramenta útil para baixar vídeos do YouTube, Vimeo, DailyMotion etc. \\
\hline ClassDojo & Para relatórios de gestão sobre o comportamento dos alunos, bastante útil para compartilhar com os pais. \\
\hline Animoto & $\begin{array}{l}\text { Considerada por muitos como a melhor ferramenta para criar vídeos online a partir de material multimídia } \\
\text { (fotos, vídeos, texto, etc.), armazenado localmente no computador ou simplesmente utilizando o disponível na } \\
\text { rede. }\end{array}$ \\
\hline Todaysmeet & Rápida opção para criar salas de bate papo (chat). \\
\hline Slideshare & $\begin{array}{l}\text { Opção útil para criar e compartilhar apresentações com slides desde um canal pessoal, permitir sua } \\
\text { visualização e um espaço para comentários. }\end{array}$ \\
\hline Voki & Ferramenta que permite criar um avatar que fala, acompanhando as lições multimídia. \\
\hline RecordMP3 & Para gravar e compartilhar áudio em mp3. \\
\hline Prezi & $\begin{array}{l}\text { Excelente opção para substituir as apresentações do Microsoft PowerPoint, o Prezi eleva a um novo nível as } \\
\text { apresentações graças às suas ferramentas interativas, visualizações dinâmicas, elegantes estilos, um editor } \\
\text { realmente simples, links a conteúdo online, etc. }\end{array}$ \\
\hline Olesur & $\begin{array}{l}\text { Para criar arquivos em formato .pdf com problemas de Matemática, atividades de reforço e caligrafia, e mais } \\
\text { recursos didáticos para imprimir. }\end{array}$ \\
\hline Wiggio & $\begin{array}{l}\text { Uma das muitas potentes ferramentas para os trabalhos em grupo, com listas de tarefas, calendário, enquetes, } \\
\text { perfis e várias funções de interação. }\end{array}$ \\
\hline WordPress.org & Similar ao Blogger, do Google, na facilidade para a criação de blogs ou páginas web sobre qualquer tema. \\
\hline $\begin{array}{l}\text { YouTube para } \\
\text { escolas }\end{array}$ & $\begin{array}{l}\text { Uma versão especial do YouTube para educadores onde se poderá dispor de centenas de vídeos acadêmicos de } \\
\text { sites como YouTube EDU, Stanford e TED. }\end{array}$ \\
\hline Moodle & $\begin{array}{l}\text { Plataforma livre de aprendizagem para a criação de cursos tipo LMS, similar à BlackBoard, porém totalmente } \\
\text { gratuita, com mais ferramentas interativas e uma ampla comunidade que trabalha para seu desenvolvimento e } \\
\text { contínuo melhoramento. }\end{array}$ \\
\hline Canvas & $\begin{array}{l}\text { Ferramenta para a gestão de cursos, totalmente online (sem instalação em servidor próprio), muito mais } \\
\text { elegante e mais fácil de utilizar. }\end{array}$ \\
\hline
\end{tabular}
Fonte: Adaptado de Barroso e Antunes (2015).

Como se pode observar no quadro acima, existem inúmeras ferramentas à disposição do professor, de forma gratuita, que estão acessíveis na internet, e com tutoriais no YouTube. Deve-se considerar que tal aprendizagem requer tempo, e alguma familiaridade com as tecnologias digitais.

A seguir, conheceremos mais especificamente os Recursos Educacionais Abertos, bem como diversos repositórios que podem contribuir para a formação continuada de professores.

\subsection{Os Recursos Educacionais Abertos (REA) como ferramenta de capacitação docente a distância}

Com o surgimento da internet, veio a promessa de transformar a cultura em um produto de interação entre todos; porém, como explica Lemos (2005), essa promessa não se concretizou totalmente, devido as normas rígidas de direitos 
autorais, impulsionadas mais pela indústria que comercializa o conteúdo do que pelos próprios autores.

Assim, com o objetivo de tornar a cultura acessível, foram criados os Recursos Educacionais Abertos (REA), que são mídias e recursos didáticos disponíveis na internet com licença de uso aberta, para facilitar a criação, o uso e o compartilhamento de recursos digitais, como material educativo ou de apoio às aulas. Estes facilitam também o acesso a cursos, em especial os de Educação a Distância (EaD), oferecidos pelas instituições de ensino.

Os REA surgem como proposta para uma nova configuração de ensino e aprendizagem, proporcionando a Educação Aberta por meio de acesso ao ensino pelas mídias digitais e do uso dos novos recursos tecnológicos que buscam levar a aprendizagem onde a escola tradicional não consegue chegar. Podem ser considerados materiais utilizados na educação em quaisquer suportes ou mídias como livros didáticos, textos, vídeos, softwares e outros materiais digitais que estejam disponíveis numa licença flexível ou em domínio público em formatos preferencialmente abertos ou livres para que outros possam usar, copiar, modificar, remixar e adequar aos diferentes contextos de trabalho ou sala de aula (NETO; GARCIA, 2013).

Os Recursos Educacionais Abertos apresentam duas características principais: a) a abertura técnica do seu formato, ou seja, a utilização de recursos didáticos de fácil manipulação em softwares, em especial os softwares livres que facilitam o acesso e a reutilização dos recursos educacionais e, b) a presença da licença aberta, que facilita o uso legal a todos que desejam ter acesso a esses materiais educacionais servindo como alternativa para diminuir os custos da educação e valorizando as práticas educacionais abertas que apoiam a criação, o uso e reutilização de tais recursos.

Seu grande diferencial em relação aos outros recursos é a flexibilidade, que torna possível fazer combinações com outros recursos, permitindo a criação de um novo, e ainda aprimorar e adaptar o novo recurso ao contexto educacional, usar e compartilhar, tornando-o disponível para outros usuários. É possível encontrar os REA's na internet, utilizando as ferramentas de busca e em sites denominados repositórios online, que são os sites que disponibilizam recursos digitais. São considerados repositórios, os serviços online que disponibilizam objetos de aprendizagem e recursos digitais. No Brasil, a maior parte do acervo existente é mantida por universidades e instituições governamentais (SILVA, 2014).

Sites de busca como o Google apresentam filtros de direitos de uso nas páginas de pesquisa avançada com opções que mostram as páginas que estão marcadas com uma licença - Creative Commons - ou marcadas como de domínio público. A proposta do Creative Commons é criar um universo de bens culturais que possam ser acessados ou transformados, de acordo com a autorização voluntária do autor. "Por meio delas, um autor de um filme ou canção pode dizer ao mundo que ele não se importa com alguns usos do trabalho dele, enquanto mantém reservados todos os outros direitos autorais sobre a obra" (LEMOS, 2005, p.184).

Diversos repositórios podem contribuir para a formação continuada de professores. O Portal do Professor possui um dos maiores acervos brasileiros de REA, onde encontramos diversos materiais de apoio para o professor, incluindo recursos multimídia, áudio, vídeo, imagem, animação, hipertexto e software em diversas áreas do conhecimento voltado para o público do ensino fundamental e médio. Os seus conteúdos possuem a licença Creative Commons ou foram cedidos pelos seus autores com a devida licença para a visualização, cópia, distribuição ou tradução, não podendo ser usados para finalidade lucrativa.

O Banco Internacional de Objetos Educacionais (BRASIL, 2009), criado em 2008 pelo Ministério da Educação em conjunto com o Ministério da Ciência e Tecnologia e outras organizações, está integrado ao Portal do Professor ${ }^{1}$ e tem como objetivo manter e compartilhar recursos educacionais digitais de livre acesso em formatos diversos. O seu acervo está disponível para todo o público e catalogado por níveis de ensino: Educação Infantil, Ensino Fundamental, Ensino Médio e Educação Profissional e Superior. Há também outros dois repositórios online no Portal do Professor: o Domínio Público e a TV Escola que também pertencem ao Ministério da Educação. ${ }^{2}$

O Domínio Público é uma biblioteca virtual que compartilha obras literárias, artísticas e científicas que fazem parte do patrimônio cultural brasileiro e universal em diversos formatos que já se encontram em domínio público ou com a devida licença autorizada pelos detentores dos seus direitos autorais.

A TV Escola é um canal aberto a todos que desejam aprender e funciona como uma ferramenta pedagógica para ser utilizada pelo professor em suas práticas de ensino. Seu objetivo é ser um espaço de colaboração tanto para a ação do educador com os alunos, quanto para seu próprio aperfeiçoamento. Conta com recursos muito interessantes, entre os quais: filmes, depoimentos, debates, fóruns, palestras, como ressaltam Neto e Garcia (2013).

Como já dito aqui, o Portal do professor, o Banco Internacional de Objetos Educacionais, a TV Escola e o Domínio Público estão integrados e fazem parte de uma parceria do Ministério da Educação e o Ministério de Ciência e Tecnologia. O RIVED (Rede Interativa Virtual de Educação) é outro repositório importante que também é mantido pelo ministério da Educação em parceria com a Secretaria de Educação a Distância, e produz objetos de aprendizagens com 
o objetivo de serem utilizados nas mais variadas disciplinas da rede pública de ensino e instituições de ensino superior. Tem também como função promover a produção e publicação desses conteúdos digitais para acesso gratuito na web. Os conteúdos produzidos são públicos e estão sendo licenciados pelo Creative Commons garantindo os direitos autorais dos conteúdos publicados e possibilitando que outros possam copiar e distribuir o material; é exigido apenas que se atribua o crédito aos autores, e desta forma tornam-se um recurso educacional aberto (NETO; GARCIA, 2013).

\section{Conclusão}

O artigo apresentou diversas ferramentas digitais disponíveis para aplicação na área educacional facilmente acessadas na internet, evidenciando que para seu uso, o professor precisa ter noções mínimas de navegação na internet, saber como pesquisar, e aprender a aprender, comportamento esse que ele deve também desenvolver nos educandos.

Como alternativa de formação continuada a distância, o artigo apresentou os Recursos Educacionais Abertos (REA), que são considerados serviços online que disponibilizam objetos de aprendizagem e recursos digitais, mantidos em sua maioria por universidades e instituições governamentais.

Foram apresentados diversos portais que fazem parceria entre o Ministério da Educação e o Ministério de Ciência e Tecnologia: o Portal do professor, o Banco Internacional de Objetos Educacionais, a TV Escola e o Domínio Público; assim como o RIVED (Rede Interativa Virtual de Educação), outro importante repositório mantido pelo ministério da Educação em parceria com a Secretaria de Educação a Distância, o qual produz objetos de aprendizagens com o objetivo de serem utilizados nas mais variadas disciplinas da rede pública de ensino.

Conclui-se que o perfil do professor para atender às necessidades atuais da Educação Básica, deve estar o mais próximo possível de um mediador e provocador da aprendizagem, fazendo o possível para levar aos educandos os conhecimentos, através de meios diversificados. Apesar dessa necessidade, verifica-se que o professor ainda enfrenta muitas dificuldades para atingir uma atuação completa e eficaz com o uso das ferramentas digitais, especialmente pelas deficiências da formação inicial. Portanto, as instituições, e na ausência destas, o próprio professor, deve buscar o aperfeiçoamento profissional através da formação continuada.

Espera-se ao apresentar ferramentas e repositórios com licença de uso aberta, que facilitam a criação, o uso e o compartilhamento de material educativo ou de apoio às aulas, tenha contribuído na indicação de alternativas viáveis.

\section{Referências}

BALADELI, A. P. D.; BARROS, M. S. F.; ALTOÉ, A. Desafios para o professor na sociedade da informação. Educar Rev., n.45, p.155-165, 2012.

BARROSO, F.; ANTUNES, M. Tecnologia na educação: ferramentas digitais facilitadoras da prática docente. Pesq. Debate Educ., v.5, n.1, p.124-131, 2015.

BRASIL. Banco Internacional de Objetos Educacionais. Secretaria de Educação a Distância. Ministério da Educação. 2009. Disponível em: <https://objetoseducacionais.mec.gov.br>. Acesso em: 30 nov. 202020.

LEITE, W. S. S.; RIBEIRO, C. A. N. A inclusão das TICs na educação brasileira: problemas e desafios. Magis. Rev. Int. Investig. Educ., v. 5, n.10, 173-187, 2012.

LEMOS, R. Creative Commons, mídia e as transformações recentes do direito da propriedade intelectual. Rev. Direito GV1, v.1, n.1, p.181-187, 2005.

LOPES, P.M.A.; MELO, M.F.A.Q. O uso das tecnologias digitais em educação: seguindo um fenômeno em construção. Psicol. Educ., v.38, p.49-61, 2014.

NETO, F.M.S.; GARCIA, M.L.S. Recursos educacionais abertos para EAD. CONGRESSO BRASILEIRO DE ENSINO SUPERIOR A DISTÂNCIA, 10, 2013, Belém. In: Anais... Belém: UNIREDE, PA, 2013, p. 1-11.

OLIVEIRA, M.G.L. A capacitação do professor para o uso das tecnologias da informação e comunicação. Intermeio, v.9, n.18, p.90-103, 2003.

SILVA, R.D.S. Nativos e imigrantes digitais no contexto educacional. João Pessoa: Universidade Estadual da Paraíba, 2014.

VALENTE, J.A. (Org.). O computador na sociedade do conhecimento. Campinas: Unicamp, 1999.

VALENTE, J.A.; ALMEIDA, F.J. Visão analítica da informática na educação no Brasil: a questão da formação do professor. Rev. Bras. Inform. Educ. n.1, p. 45-60, 1997.

WERTHEIN, J. A sociedade da informação e seus desafios. Rev. Ciênc. Inform, v. 29, n.2, p.71-77, 2000.

VELLOSO, F. Informática: conceitos básicos. Rio de Janeiro: Elsevier, 2014. 